\title{
A Glycan FRET Assay for Detection and Characterization of Catalytic Antibodies to the Cryptococcus neoformans Capsule
}

\author{
Conor J. Crawford' ${ }^{1,2}$, Maggie P. Wear ${ }^{2}$, Daniel F. Q. Smith², Clotilde d'Errico', Scott A. McConnell², \\ Arturo Casadevall ${ }^{2 *}$, Stefan Oscarson ${ }^{1 *}$ \\ ${ }^{1}$ Centre for Synthesis and Chemical Biology, University College Dublin, Belfield, Dublin, Ireland, \\ ${ }^{2}$ Department of Molecular Microbiology and Immunology, Johns Hopkins Bloomberg School of Public \\ Health 615 North Wolfe Street, Baltimore, MD 21205, USA
}

*Arturo Casadevall, Stefan Oscarson share senior authorship

Email: stefan.oscarson@ucd.ie and acasade1@jhu.edu

\section{ORCID ID}

Conor Crawford orcid.org/0000-0002-1314-1019, Arturo Casadevall E-mail: acasade1@jhu.edu, Stefan Oscarson orcid.org/0000-0002-8273-4918 E-mail: stefan.oscarson@ucd.ie

\section{Keywords}

Glycan, FRET Probe, Catalytic Antibody, Oligosaccharides, glucuronoxylomannan,

\section{Author Contributions}

C.J.C, A.C and S.O wrote the original draft. C.J.C completed the synthesis. C.J.C and C.D.E printed and screened the glycan array. C.J.C cultured and isolated mAbs. C.J.C, M.P.W, D.F.Q.S completed the kinetic analysis. C.J.C completed the docking studies. C.J.C completed the capsule measurement experiments. D.F.Q.S, M.P.W, and S.A.M. completed the immunofluorescence experiments. S.A.M. and M.P.W. complete the phagocytic index experiments. All authors edited manuscript. C.J.C, A.C, S.O funding acquisition. 


\begin{abstract}
Classical antibody functions include opsonization, complement activation, and enhancement of cellular antimicrobial function. Antibodies can also have catalytic activity, although the contribution of catalysis to their biological functions has been more difficult to establish. With the ubiquity of catalytic antibodies against glycans virtually unknown, we sought to advance this knowledge. The use of a glycan microarray allowed epitope mapping of several monoclonal antibodies (mAbs) against the capsule of Cryptococcus neoformans. From this, we designed and synthesized two glycan based Förster Resonance Energy Transfer (FRET) probes, which we used to discover antibodies with innate glycosidase activity and analyse their enzyme kinetics, including $\mathrm{mAb} 2 \mathrm{H} 1$, a polysaccharide lyase, and the most efficient glycosidase to date. The validity of the FRET assay was confirmed by demonstrating that the mAbs mediate glycosidase activity on intact cryptococcal capsules, as observed by a reduction in capsule diameter. Further the mAb 18B7, a glycosidase hydrolase, resulted in the appearance of reducing ends in the capsule as labelled by hydroxylamine-armed fluorescent (HAAF) probe. Finally, we demonstrate that exposing $C$. neoformans cells to catalytic antibodies results in changes in complement deposition and increased phagocytosis by macrophages - suggesting the anti-phagocytic properties of the capsule have been impaired. Our results raise questions over the ubiquity of antibodies with catalytic activity against glycans and establish the utility of glycan-based FRET and HAAF probes as tools for investigating this activity.
\end{abstract}

\title{
Significance Statement
}

Cryptococcus neoformans is a global fungal pathogen that is a frequent cause of a life-threatening meningoencephalitis. There is a need for new therapies and vaccines. A better understanding of antibodies associated with its major virulence factor, the capsule, will allow the development of new antibody-therapeutics, inform vaccine design and further basic knowledge of antibody structurefunction. We demonstrate several antibodies against the capsule have innate glycosidase activity, and these antibodies can cause hydrolyse of the native capsule, resulting in a disruption of cellular integrity. To date identifying this elusive quality in antibodies has been difficult. We have simplified this process by the development of a high-throughput FRET assay. This approach could be generalized to identify other antibodies catalytic against glycans. 


\section{Introduction}

Humans are protected from infectious diseases by physical defences, endothermy, and an advanced immune system that includes both innate and adaptive arms (1). One of the remarkable aspect of adaptive immunity is the generation of specific antibodies against microbial antigens, which aid the hosts immune defence against infection. Antibodies also serve as valuable research tools, diagnostics, and therapeutics (2). Further, some antibodies manifest catalytic activity to cleave antigens and possess intriguing innate capabilities such as catalysing the breakdown of oxygen into hydrogen peroxide (3-6). The existence of catalytic antibodies was first hypothesized by biochemist Jencks in the 1980s, using the framework of Pauling that if an antibody was raised against a transition state analogue it could possibly cleave its substrate. Over the last three decades catalytic antibodies have been an area of intensive research (7-9).

In an effort to develop therapies against Cryptococcus neoformans, an opportunistic fungus that is estimated to infect 1 million annually, with over 600,000 deaths (10), several glycoconjugate vaccine candidates were developed using synthetic and native polysaccharides based on the C. neoformans capsule (11-13). The capsule is composed of several constituents but the glucuronoxylomannan (GXM) dominates, accounting for $95 \%$ of capsule mass (14-16). Using hybridoma technology monoclonal antibodies have been developed against the GXM (2), with one antibody, 18B7, used in a phase I clinical trial as a candidate for passive antibody therapy for cryptococcal infections (17). In later years, this antibody and others were serendipitously discovered to have catalytic activity against peptide mimetics of the GXM, further, indirect methods of analysis suggested glycosidase activity $(4,6)$. However, the lack of tools left many questions unanswered about their catalytic activity against their native glycan antigens.

The physiological role(s) of catalytic antibodies in immunity are currently unresolved. For example, catalytic antibodies are found in both patients with healthy outcomes and autoimmune conditions (18). One particular area where antibody catalysis may be relevant is in infectious diseases, as catalytic antibodies could be effective, even if relatively slow, against microbial antigens since these infections often develop over a long time, which could permit even slow catalytic rates to have an effect (19). The prevalence of innate glycosidase activity in antibodies is unknown and is particularly interesting when one considers the importance of antibodies against bacterial polysaccharides in acquired immunity. Catalytic mAbs could work through cleaving immunosuppressive polysaccharide capsules, revealing more immunogenic epitopes to the immune system, aiding immune detection and increasing the potency of antibody-dependent cellular cytotoxicity.

Herein, we report the design and synthesis of two glycan FRET probes to understand the prevalence of innate glycosidase activity in antibodies against the cryptococcal capsule. To date identifying this elusive quality in antibodies was difficult to establish but we show through rational design of glycan-based FRET probes that glycosidase activity can be both identified and characterized. This approach could be generalized to identify other antibodies catalytic against glycans. In our study, we highlight the enzymatic properties of four monoclonal antibodies (mAbs) against the GXM, revealing intrinsic differences with regards to epitope specificity and isotype. 


\section{Results}

\section{Antibody Epitope Mapping}

Recently we have developed a synthetic glycan array containing a library of GXM structures (20). When screening this library with mAbs to $C$. neoformans GXM we found a decasaccharide that was recognized by a wide variety of antibodies (20). Consequently, we selected it as a good structure for the development into a FRET probe to serve as a potential assay to identify catalytic antibodies. The synthesis of GXM related glycans are complicated by the presence of a 6-O-acetylation pattern. This $O$-acetylation is important for GXM antibody recognition but severely limits protecting group strategies $(21,22)$. To establish whether $O$-acetylation was important for oligosaccharide binding, we conducted a microarray study (Fig. 1A), which revealed that the binding to the non-acetylated decasaccharide was significantly diminished for mAb 18B7 and for all other mAbs screened binding was lost entirely (Fig. $1 \mathrm{~A})$. Consequently, we synthesized the more chemically challenging acetylated FRET probes.

\section{Design and Synthesis of FRET Probes}

We envisaged using the aminoalkyl linker present at the reducing end as a handle for the attachment of one-half of the FRET pair, then use another orthogonally protected amine at the non-reducing end, allowing selective attachment of the fluorophore and quencher, to access the desired glycan FRET probes (Scheme 1). Synthesis and assembly of the required building blocks for GXM assembly followed published protocols $(20,23-29)$. Through a convergent building block approach we achieved the synthesis of the bifunctionally armed decasaccharide. Briefly, disaccharide acceptor 1 was coupled with thioglycoside donor 2 using DMTST in ether giving total 1,2-trans selectivity (30), following purification the 2-naphthylmethyl (NAP) ether was removed using oxidative conditions to yield tetrasaccharide acceptor 4 (Scheme 1A). This was then coupled with a glucuronic acid containing disaccharide 5 to give hexasaccharide 6 , solely as the $\alpha$-anomer in $63 \%$ yield. Again, the orthogonal NAP group was chemoselectivity cleaved to access hexasaccharide acceptor $\mathbf{7}$. The tetrasaccharide 8 was then assembled using inverse-glycosylation conditions as described by Guazzelli et al. (31), and the aminopropyl handle successfully attached to its free 3 '-OH group under alkylating conditions, in the presence of the 6 -O-acetyl group $(\rightarrow \mathbf{9}, 70 \%$ isolated yield), with only minor de-acetylation occurring ( $8 \%$ of isolated yield) (Scheme 1B). Donor 9 was then used successfully in a coupling with acceptor 7 to create the $\mathrm{N}$-orthogonally functionalized decasaccharide 10 , as the sole anomer in $85 \%$ yield. The $\mathrm{N}$-phthalimido protecting group was then selectively removed in the presence of the 6-O-acetylation pattern using ethylenediamine, followed by formation of the $N$-Boc protected compound 11 in $57 \%$ yield. Decasaccharide 12 was then subject to palladium catalysed hydrogenolysis, to remove benzyl protecting groups and reduce the linker azido group to an amine, using our developed optimized conditions, yielding 13 after P-2 size exclusion chromatography (Scheme 1B) $(28,32)$.

Subsequently, due to the limited quantity of material available it was decided to telescope the final steps to minimalize the loss of material. Firstly, the fluorophore was conjugated to the amino linker using an $\mathrm{N}$-hydroxysuccinimide (NHS) active ester of 7-methoxycoumarin-4-acetic acid (MCA), to produce compound 14 (Fig. 1B). Subsequently, the $\mathrm{N}$-Boc group was removed using an aqueous mixture of $3 \mathrm{M} \mathrm{HCl}$ methanol to produce 15 . The final conjugation was carried out using the NHS activated $\mathrm{N}$-(2,4-dinitrophenyl) glycine (DNP) to give $5.4 \mathrm{mg}$ of the target desired FRET probe 16 in $56 \%$ overall yield over the three steps. Despite the initial evidence that non-acetylated structures are poorly recognized in the microarray assay (Fig. 1A), we decided to further investigate the importance of the 6-O-acetylation pattern in the antibody recognition and possible catalysis in solution. Deacetylation of a portion of the decasaccharide FRET-OAc probe under basic conditions yielded $2 \mathrm{mg}$ of FRET probe 17. The two probes are termed FRET-OAc (16), for the decasaccharide with acetyl groups, and FRET (17) for the non-acetylated decasaccharide.

\section{A FRET Assay to Detect Catalytic Antibodies}

Four murine monoclonal antibodies were investigated: $18 \mathrm{~B} 7\left(\operatorname{lgG}_{1}\right), 2 \mathrm{H} 1\left(\lg \mathrm{G}_{1}\right)(33)$, and two isotypes of $3 \mathrm{E} 5$, one $\lg \mathrm{G}_{1}$ and one $\operatorname{lgG}_{3}$, which have identical variable regions but differ in the constant region (34). mAbs $2 \mathrm{H} 1,18 \mathrm{~B} 7$ and $3 E 5\left(\operatorname{lgG}_{3}\right)$ were generated from $B$ cells harvested from the spleen on mice immunized with a GXM-tetanus toxoid conjugate vaccine $(21)$, while $m A b 3 E 5\left(\operatorname{lgG}_{1}\right)$ was generated by in vitro isotype switching. Each of these mAbs bind to the GXM capsular polysaccharide of C. neoformans. mAbs $18 \mathrm{~B} 7$ and two 3E5 isotypes ( $\operatorname{lgE}$ and $\operatorname{lgA}$ ) were previously shown to catalyze cleavage of a peptide mimetic of the GXM, termed P1 (SPNQHTPPWMLK) $(4,5)$. To determine if this activity extended to the oligosaccharide binding targets, mAbs 18B7, 3E5 (lgG $\left.)_{1}\right), 3 E 5\left(\operatorname{lgG}_{3}\right)(800$ 
$\mu \mathrm{g} / \mathrm{mL})$ and $2 \mathrm{H} 1(580 \mu \mathrm{g} / \mathrm{mL})$ were incubated with $400 \mu \mathrm{M}$ of either the oligosaccharide FRET-OAc or FRET probe in a fluorescence spectrometer $\left(\lambda_{\mathrm{ex}} 320 \mathrm{~nm} \lambda_{\mathrm{em}} 405 \mathrm{~nm}\right)$ at $37^{\circ} \mathrm{C}$ for 70 hours (Fig. 2). $\mathrm{mAb} 18 \mathrm{~B} 7$ showed moderate catalytic activity towards both FRET probes, while mAb 3E5 (IgG 1$)$ displayed comparable results to $\mathrm{mAb} 18 \mathrm{~B} 7$ when incubated with both FRET probes. Interestingly, the $\lg \mathrm{G}_{3}$ variant of $3 \mathrm{E} 5$ differed in specificity towards the two $\mathrm{FRET}$ probes when compared to $3 \mathrm{E} 5\left(\lg \mathrm{G}_{1}\right)$, despite having the same variable sequence. In contrast to the $\lg _{1}$ variant, $3 \mathrm{E} 5\left(\operatorname{lgG}_{3}\right)$ displayed no catalytic activity towards the FRET probe but showed the second highest efficiency in cleaving the FRET-OAc probe. mAb $2 \mathrm{H} 1$ caused the greatest cleavage of the FRET-OAc probe, while showing similar levels of low activity towards the FRET probe as mAbs $18 \mathrm{~B} 7$ and $3 \mathrm{E} 5$ ( $\left(\operatorname{lgG}_{1}\right)$ (Fig. 2).

\section{Michaelis-Menten Kinetics of Antibodies Catalytic Against Glycans}

Next, we sought to determine the Michaelis-Menten (MM) kinetics of mAbs against both FRET probes. To investigate, we incubated both antibodies with varying concentrations of the FRET probes 16 or 17 and plotted the change in velocity $\left(\mathrm{V}_{0}\right)$ as a function of substrate concentration (Table 1 , See SI Appendix, Fig. 4). In the case of $\mathrm{mAb}^{3} \mathrm{E}^{-}-\mathrm{IgG}_{3}$ no breakdown was observed, mirroring the assay result, meaning we were unable to determine its MM kinetics towards the deacetylated FRET probe. This was not the case for isotype switch variant $\mathrm{mAb}_{3 \mathrm{E} 5}-\mathrm{IgG}_{1}$, thus by virtue of $3 \mathrm{E} 5-\mathrm{IgG}_{3}$ mAbs lack of activity, we note that $m A b 3 E 5-\lg G_{1}$ was superior at breakdown of the FRET probe (Table 1, Entry 3 and 4). In the case of FRET-OAc we managed to determine the kinetics for both 3E5 mAbs (Table 1, Entry 7 and 8). Comparison of the two $3 \mathrm{E} 5$ isotype variants revealed they have similar $K_{\mathrm{m}}$ values but $\mathrm{mAb} 3 \mathrm{E} 5-\lg \mathrm{G}_{3}$ presented to have a higher turnover number $\left(k_{c a t}\right)$ meaning it had a higher catalytic efficiency towards the FRET-OAc probe (Table 1, Entry 7 and 8 ).

The MM kinetics of $\mathrm{mAb} 18 \mathrm{~B} 7$ against the $\mathrm{P} 1$ peptide has been described by Bowen et al. (4). While the $K_{m}$ of mAb 18B7 towards the P1q FRET peptide ranged from 46 to $55 \mu \mathrm{M}$, our results showed $\mathrm{mAb} 18 \mathrm{~B} 7$ has much lower $\mathrm{K}_{\mathrm{m}}$ for the glycan substrate compared to the peptide. This is not surprising given that this antibody was raised against the polysaccharide capsule. The $k_{c a t}$ values of mAb 18B7's cleavage of the FRET probes was also at least 2-fold of that measured for mAb 18B7s cleavage of the P1q peptide (FRET peptide, $1 \times 10^{-2} \mu^{-1} / \mathrm{s}^{-1}$ ).

For $m A b 2 \mathrm{H} 1$, we were able to calculate the MM kinetic parameters for mAb $2 \mathrm{H} 1$ against both FRET probes (Table 1, Entry 2 and 6). $\mathrm{mAb} 2 \mathrm{H} 1$ had a lower $\mathrm{K}_{\mathrm{m}}$ for the acetylated FRET probe and overall a higher catalytic efficiency towards the breakdown of the FRET-OAc probe (Table 1, Entry 2 and 6). Overall, when comparing each mAbs catalytic efficiency towards both FRET probes, it was clear mAb $2 \mathrm{H} 1$ was most the efficient at cleaving both the FRET and FRET-OAc probes, therefore we focused the rest of our investigation on $\mathrm{mAb} 2 \mathrm{H} 1$ to hopefully gain insights into the most efficient antibody identified to date with innate catalytic activity against glycans.

\section{Antibody $2 \mathrm{H} 1$ has peptidase activity}

The GXM mimetic, P1 (SPNQHTPPWMLK) $(4,5)$ when incubated with mAb $2 \mathrm{H} 1$ at $37^{\circ} \mathrm{C}$ resulted in cleavage of the $\mathrm{P} 1$ peptide, as was suggested by the disappearance of the parent material ion $1435.7 \mathrm{~m} / \mathrm{z}$, and the appearance of fragment ions (See SI Appendix, Fig. S2). In particular, the ion $690.9 \mathrm{~m} / \mathrm{z}$ corresponded to cleavage between threonine and proline (SPNQHT/PPWMLK) but it was not possible to identify the other half of this fragment at $769.4 \mathrm{~m} / \mathrm{z}$ (PPWMLK). This suggests $\mathrm{mAb} 2 \mathrm{H} 1$ causes cleavage between the same residues as mAb 18B7 (threonine and proline) but differed to the cleavage pattern of the 3E5 antibodies (SPNQHTPPWM/LK)(4). Next, we used a P1q FRET $(200 \mu \mathrm{M})$ peptide recently described by Bowen et al. (4), which confirmed that $2 \mathrm{H} 1(375 \mu \mathrm{g} / \mathrm{mL})$ had enzymatic activity towards the peptide probe but at much lower levels than 18B7 (See SI Appendix, Fig. 1C, 1D).

\section{Antibody $2 \mathrm{H} 1$ is a GXM Lyase}

To gain understanding of how the antibodies were breaking down GXM, we incubated mAbs $2 \mathrm{H} 1$ and 18B7 with a synthetic oligosaccharide for $2 \mathrm{~d}$ at $37^{\circ} \mathrm{C}$ (Fig. 1, acetylated decasaccharide). Mass spectrometry analysis of how mAb 18B7 hydrolyses the GXM was reported previously(4), and was again confirmed by our experiments finding an ion corresponding to a hexasaccharide $(1116.0 \mathrm{~m} / \mathrm{z}$, See SI Appendix, Fig. 9), suggesting cleavage along the mannose backbone, specifically between third and fourth mannose from the reducing terminus, representing an endoglycosidase like activity.

In the mAb $2 \mathrm{H} 1$ incubation breakdown was suggested by disappearance of the parent ion and the appearance of fragments, initially we sought to identify the products of hydrolysis but were unable to do so. Noting that polysaccharide breakdown can also occur through more unconventional 
mechanisms(35), such as those of polysaccharide lyases (36), prompted us to wonder if mAb $2 \mathrm{H} 1$ proceeded through this mechanism. Further analysis of the mass spectra allowed the successful identification of the 1,2-enol ether breakdown products (See SI Appendix, Fig. 10) $(35,36)$. Two distinct cleavage products were identified, which corresponded to cleavage along the mannose backbone either side of the internal $\beta-1,2$ glucuronic acid mannose disaccharide moiety, with the presence of the distinctive enol ether fragments confirmed. Overall our results and previous mass spectrometry analysis of $18 \mathrm{~B} 7$ (4), suggest that $\mathrm{mAbs} 18 \mathrm{~B} 7$ and $2 \mathrm{H} 1$ operates through enzymatically distinctive mechanisms for GXM breakdown.

\section{Absence of Classical Catalytic Residues in 2H1 Paratope}

The proteolytic catalytic activity of $\mathrm{mAb} 18 \mathrm{~B} 7$ was recently studied in detail and catalytic residues were proposed (4), however a crystal structure for 18B7 does not yet exist. In contrast, a crystal structure of the fragment antigen-binding ( $F a b)$ domain of $\mathrm{mAb} 2 \mathrm{H} 1$ bound to a peptide mimetic of $\mathrm{GXM}$ was solved by Young and co-workers (Fig. 3B) (37). Using the PDB file and the open access modelling server GLYCAM(38-40), we performed antibody docking studies to determine the glycan-antibody interactions for 2H1 (Fig. 3A, 4). We performed docking studies with both acetylated (See SI Appendix, Fig. 6) and deacetylated (Fig. 3) GXM structures, with the highest scoring binding affinities predicted to be -10 $\mathrm{kcal} / \mathrm{mol}$ for both acetylated and deacetylated structures. When we applied an adaptive PoissonBoltzmann solver (APBS) to the $2 \mathrm{H} 1 \mathrm{Fab}$, it revealed an electropositive cleft (Fig. 3B). Considering that GXM is an anionic polysaccharide, this electropositive cleft suggests a role for ionic interactions in affinity between the antibody and antigen. The highest scoring docked structures predict that the carboxylic acid moiety of glucuronic acid residue engaging in hydrogen bonding with asparagine residue 33 (ca. 3Å) (Fig. 4). The importance of xylose side-chains was also apparent by the modelling results with the highest scoring docking structures having xylose branches in pockets underneath tyrosine and phenylalanine residues, possibly being stabilized by $\mathrm{CH} / \pi$ stacking (Fig. 4) (41). We also sought through modelling to discern the residues responsible for catalysis, and while no definitive assignment was possible, it was clear that no classical catalytic residues were present in the antigen binding site

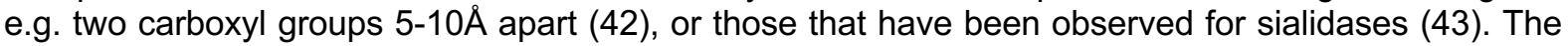
classical Ser-His-Asp catalytic triad, that was proposed by Bowen et. al. to be responsible for the cleavage of the $\mathrm{P} 1$ peptide by $18 \mathrm{~B} 7$ was also absent from mAb 2H1(4). Despite the absence of conventional glycosidase motifs, there was an abundance of nucleophilic amino acids - tyrosine, histidine, and asparagine, which could work in tandem to produce acid-base catalysis to promote the observed glycosidase activity. In future work mutagenesis experiments will be required in order to determine the residues responsible for catalysis.

\section{GXM Secondary Structure}

Using GLYCAM carbohydrate builder, we predicted the conformations of acetylated and non-acetylated decasaccharide, to try and better understand this phenomenon (38-40). In both models GXM adopts a helical conformation due to the $\alpha$-mannose backbone, that is decorated by branching of $\beta$-xylose and $\beta$-glucuronic acid residues (Fig. $3 \mathrm{C}$ ). Molecular modelling predicts that the mannan backbone conformation is not altered by acetylation of GXM (See SI Appendix, Fig. 5). However, acetylation does create new epitopes and a hydrophobic substituent, which may allow increased antibody binding, which could explain the differences observed for acetylated and non-acetylated structures. When performing GXM modelling and antibody-antigen docking experiments, it became apparent that the P1 peptide and decasaccharide both adopted a helical conformation, both bound to the same binding site, making the peptide a "mimotope" - mimics of epitopes, something previously hypothesized and experimentally demonstrated previously through ELISA (Fig. 3C, See SI Appendix, Fig. 1A, 1B) (4-6).

\section{Catalytic Antibodies Perturb Capsule and Cellular Integrity}

To discern if the glycosidase activity on the FRET probes was predictive of activity on the native capsule, we incubated cells with $10 \mu \mathrm{g} / \mathrm{mL}$ of $\mathrm{mAbs} 2 \mathrm{H} 1,18 \mathrm{~B} 7$, control $\mathrm{lgG}$ or no antibody for a week with heat killed $\mathrm{H} 99 \mathrm{C}$. neoformans cells, at $30^{\circ} \mathrm{C}$ with agitation. After a week, the capsule diameter was not altered in the absence of antibody or after incubation with the control $\lg \mathrm{G}_{1}$ antibody. In contrast, cells incubated with mAbs $2 \mathrm{H} 1$ or $18 \mathrm{~B} 7$ showed a significant decrease in mean capsule diameter $(p<$ $0.0001)$. The reduced capsule diameter could suggest capsule breakdown through a glycosidase mechanism. We also observed a population of cells incubated with either $18 \mathrm{~B} 7$ or $2 \mathrm{H} 1$ had lost the majority of their capsule (Fig. 5A, 5B), possibly indicating capsular heterogeneity, and differing 
susceptibility to antibody-mediated catalysis - even when using the same strains, under the same growth conditions $(4,14,16)$.

Next, we sought to determine whether the observation of the decrease in capsule diameter was the result of glycosidase activity on the GXM. To do so we devised an experiment using the hydroxylamine-armed fluorescent (HAAF) probe that we recently used to explore the architecture of the $C$. neoformans capsule (44). That study was remarkable in that reducing ends were only visualized at the cell wall-capsule interface and not within the capsule body itself. We reasoned that if the mAbs were hydrolysing capsular GXM we may see the appearance of HAAF probe related staining in extracellularly or in the capsule body. To examine this, we incubated catalytic antibodies 2H1 and 18B7, a control mAb, and no mAb, with heat-killed C. neoformans cells. After 3 and 7 days cells were visualized through fluorescence microscopy, using fluorescent anti-lgG secondary antibodies (red), and an HAAF probe (green) (44). On day 3, no staining of the hydroxylamine probe occurred in the capsule (See SI Appendix, Fig. 7, 8). However, on day 7, we observed the appearance of HAAF probe related staining in the capsule of $18 \mathrm{~B} 7$ but none in mAb $2 \mathrm{H} 1$ or in controls (Fig. $5 \mathrm{C}$ ). The absence of staining in the $2 \mathrm{H} 1 \mathrm{mAb}$ incubation was further evidence of its lyase activity. As by virtue of the HAAF probes mechanism - it will only stain reducing end glycans and not label the enol ether related breakdown products of $2 \mathrm{H} 1$.

\section{Catalytic Antibodies Alter Complement Deposition and Enhance Phagocytosis by Macrophages}

To investigate if there was any biological significance to $\mathrm{mAb} 2 \mathrm{H} 1$ mediated catalytic activity on the cryptococcal capsule, we removed the antibody after 7 days of incubation (gentle elution buffer, $\mathrm{pH}$ 6.6) from the cells and added C3 complement (Supplier info?). Previously, complement has been shown to bind to the capsule of $\mathrm{H} 99$ cells in an annular pattern, ultimately resulting in enhanced antibody mediated phagocytosis (45). Conversely, $\mathrm{H} 99$ cells incubated with mAb $2 \mathrm{H} 1$ for 7 days had highly localised complement deposition on the cell surface (Fig. 6A), suggesting the catalytic antibody changes the structure of the capsule which is visualised by alteration in complement binding to the capsule. To test if this altered complement deposition resulted in changes in phagocytosis, we studied fungal cell uptake by bone-marrow-derived macrophages (BMDMs) measuring the phagocytic index. C. neoformans cells treated with $\mathrm{mAb} 2 \mathrm{H} 1$ followed by its removal were more efficiently ingested than non-treated cells suggesting that antibody-mediated catalysis had altered the structure of the capsule, reducing its anti-phagocytic properties $\left(P^{* * *}, \leq 0.001\right)$ compared to untreated cells (Fig. $6 \mathrm{~B}, 30.5 \%$ vs. $19.8 \%)$. Catalytic antibody treated cells had comparable levels of phagocytosis $(37.1 \%)$ to cells treated with antibodies and complement alone (36.6\%), suggesting the anti-phagocytotic properties of the capsule were reduced such that macrophages ingested them to a level similar to the presence of complement alone. Phagocytosis could again be further increased by the addition of complement to antibody treated cells $(46.6 \%)$, suggesting a synergistic benefit when used in combination (Fig. 6B).

\section{Discussion}

Here we report, the design and synthesis of two glycan-based FRET probes, which, compared to their peptide counterparts, are significantly underdeveloped, having only a handful of literature reports (4651). To our knowledge, this is the first example of glycan-based FRET probes being used to resolve the kinetics of catalytic antibodies. Glycan FRET probes may find further utility in helping to characterize carbohydrate active enzymes (CAZy), and catalytic antibodies against glycans.

The glycan FRET probes used here establish that a number of antibodies against the cryptococcal capsule have innate glycosidase activity. Notably some mAbs displayed no activity towards one FRET probe but had activity towards the other (e.g. $3 \mathrm{E} \lg _{3}$ ), differences between the $\lg G_{1}$ and $\lg G_{3} m A b$ variants likely reflect constant region constraints on the IgG paratope that affect enzymatic activity. While the importance of GXM acetylation for antibody binding is noted in the literature, we observed some distinct differences in binding between the microarray binding study (Fig. 1) and FRET probes. Neither $\mathrm{mAb} 2 \mathrm{H} 1$ nor $3 \mathrm{E} 5\left(\mathrm{IgG}_{1}\right)$ bound to the deacetylated decasaccharide on the microarray but displayed glycosidase activity to the deacetylated FRET probe. There are two interpretations of this result; one that the interactions between the non-acetylated GXM and the mAb is more transient meaning that microarrays cannot reliably detect weaker glycan-protein interactions; or the addition of the aromatic and hydrophobic FRET pair affects the antibody-glycan interactions and may explain the enzymatic activity to the non-acetylated FRET probes.

In the microarray study we demonstrated the importance of acetylation on the molecular level for antibody recognition of GXM (Fig. 1A). Molecular modelling predicts no change in conformation due to acetylation, but does create new epitopes, which may be important for antibody binding by creating hydrophobic pockets to which an antibody can bind, something supported by more complex modelling, 
recently completed in collaboration with Kuttell (52). Recently, we also observed differences in cell surface hydrophobicity between serotypes of $C$. neoformans, which could be accounted for by differences in acetylation of GXM (53).

Previously, we reported that isotype switching $3 \mathrm{E} 5\left(\operatorname{lgG}_{3}\right)$ to $3 \mathrm{E} 5\left(\operatorname{lgG}_{1}\right)$ resulted in turning a non-protective antibody to a protective antibody (34). Although these differences were largely attributed to differences in constant region engagement of Fc receptors, the glycan microarray study visualized a difference in relative fluorescence units (RFU) between the two isotypes to acetylated decasaccharide (Fig. 1A). The greater RFU observed suggests $3 E 5\left(\operatorname{lgG}_{1}\right)$ is able to bind with far greater affinity to GXM, and this may also contribute to the observed differences in efficacy of the two antibodies in vivo. mAb 18B7 further followed this observed trend with similar levels of binding signal to the acetylated decasaccharide. Protective mAb $2 \mathrm{H} 1$ also displayed higher RFU to the acetylated decasaccharide than the non-protective 3E5 $\left(\operatorname{lgG}_{3}\right)$, which suggests there is a correlation between RFU for an epitope, and a mAb with protective efficacy. In the microarray study, it was also obvious that the mAbs had a 'preference' for acetylated structures, giving insight into the mammalian immune response against cryptococcal infections, suggesting a bias or competitive advantage for antibodies that recognize acetylated structures. Differences in antibody binding could originate during somatic hypermutation and subsequent selection, since acetylated structures are more hydrophobic and contain more hydrogen bond acceptors for interactions with B-cell receptors, which leads to less transient antibody-glycan interactions.

The validity of the FRET assay in reporting polysaccharide cleavage was confirmed by capsule measurement experiments and fluorescence microscopy with both experiments suggesting the capsule and cryptococcal cell surface undergo changes when exposed to catalytic mAbs $2 \mathrm{H} 1$ and $18 \mathrm{~B} 7$. While the biological importance of this effect is yet to be fully resolved - and we urge caution - it is still fascinating to consider. As the capsule is both immunosuppressive, and anti-phagocytic $(54,55)$, antibody mediated hydrolysis of the capsule in vivo could have important immunological effects, decreasing the capsule diameter, revealing more immunogenic structures, and making phagocytosis more facile by macrophages, all of which could aid the immune system to fight cryptococcal infection. Our phagocytic index experiments suggest the catalytic activity of mAb $2 \mathrm{H} 1$ results in a tangible biological effect, but further work will be required to fully resolve this elusive quality in glycan degrading antibodies. We hope, our study raises questions over the ubiquity of catalytic antibodies and what functional advantages might be given to an antibody with innate glycosidase activity against microbial or viral infection.

In summary, the use of two glycan FRET probes enabled the identification of four mAbs with innate catalytic activity towards glycans, of which mAb $2 \mathrm{H} 1$ was the most efficient. The role of mannose 6-O-acetylation in antibody recognition and catalysis was also demonstrated, by both the glycan microarrays studies and the observed kinetic differences in glycan FRET probe hydrolysis. Mass spectrometry analysis suggests $\mathrm{mAb} 2 \mathrm{H} 1$ operates in a manner that of a polysaccharide lyase enzyme, and examination of the crystal structure of $\mathrm{mAb} 2 \mathrm{H} 1$ revealed that the paratope of this antibody lacks classical glycosidase motifs. We surmise that if catalysis is achieved in the binding site, it is through a molecular mechanism yet to be discovered. The FRET probes accurately predicted catalytic activity on the native capsule, which was supported by fluorescence spectroscopy, capsule measurements, and an increased phagocytosis of cells exposed to catalytic antibodies. The approach described here utilizing FRET probes could prove very useful for the identification of catalytic activity in other glycanbinding mAbs.

\section{Methods}

Microarray Printing Glycan array printing closely followed published procedures.(56) Microarrays were constructed by piezoelectric non-contact printing (sciFLEXARRAYER S3, Scienion Inc) of the glycans on activated glass slides (Nexterion Slide H, Schott Inc). Compounds $(200 \mu \mathrm{M}, 100 \mu \mathrm{M}, 50 \mu \mathrm{M})$ were printed (drop volume $\sim 300 \mathrm{pL}, 6$ drop per spot), in replicates of 5 in sodium phosphate $(200 \mathrm{mM})$, $\mathrm{pH} 8.5$ buffer with on each slide. Overnight the slides were incubated in a humidity chamber, and the remaining activated esters were blocked with ethanolamine $(50 \mathrm{mM})$ in TRIS $(100 \mathrm{mM}), \mathrm{pH}$ 8.0. Next, slides were rinsed with MilliQ water, dried by centrifugation, and stored at $4^{\circ} \mathrm{C}$. Hybridization of arrays was performed as described previously.(56) Briefly, printed slides were blocked in a humidity chamber at $26^{\circ} \mathrm{C}$ for 2 hours with $2 \%$ BSA in PBS (pH 7.4 with $50 \mathrm{mM}$ ethanolamine), then washed 3 times for 2 minutes with PBS (pH 7.4, 0.1\% Tween-20) (PBS-T) and once for 3 minutes with PBS. 
Microarray Screening Glycan array scanning followed published procedures.(56) Primary anti-GXM mAbs or control Abs were prepared from stocks to the necessary concentration in 3\% BSA in PBS-T. Biotinylated goat anti-mouse kappa chain Abs were used as secondary reagents for all primary antibodies. Detection was performed with the streptavidin-conjugated SureLight P3 fluorophore (Cayman Chemical Company, Ann Arbor, Ml) at $5 \mu \mathrm{g} / \mathrm{mL}$ in PBS-T. Scanning was performed first with the primary $A b$, then the secondary $A b$, then the fluorophore, with washes between each step. All hybridization steps were performed using the Agilent 8-well gasket system in a humidity-controlled rotating hybridization oven at $26^{\circ} \mathrm{C}$ for $1-2$ hours. Washes (X3) in TRIS-buffered saline $(\mathrm{pH} 7.6,0.1 \%$ Tween 20) (TBS-T) for 3 minutes and once for 3 minutes in TBS. Scanning was performed in an Agilent SureScan Dx microarray scanner with red wavelength emission detection. The data was processed on Mapix software. The mean fluorescent intensities (corrected for mean background) and standard deviations (SD) were calculated $(n=6)$. Data were fitted using Prism software (GraphPad Software, Inc). Bar graphs represent the mean \pm SD for each compound.

FRET Probe Synthesis Detailed protocols for the synthesis of novel compounds and their NMR characterization can be found in supporting information. Building blocks were synthesized as described previously. $(20,24,28,57)$

Growth Conditions C. neoformans Serotype A strain H99 (American Type Culture Collection (ATCC) 208821), was grown for $48 \mathrm{~h}$ at $30{ }^{\circ} \mathrm{C}$ in capsule inducing media composed of: $10 \mathrm{mM} \mathrm{MgSO}$, 29.3 $\mathrm{mM} \mathrm{KH}_{2} \mathrm{PO}_{4}, 13 \mathrm{mM}$ glycine, $3 \mu \mathrm{M}$ thiamine-HCl; adjusted to $\mathrm{pH} 5.5$ and supplemented with $15 \mathrm{mM}$ dextrose.

Kinetic experiments FRET experiments were completed as reported by Bowen et al.(4) Using a SpectraMax M5 microplate reader (Molecular Devices), at $37^{\circ} \mathrm{C}$. An excitation wavelength of $320 \mathrm{~nm}$, an emission wavelength of $405 \mathrm{~nm}$, and an emission cut-off filter of $325 \mathrm{~nm}$.

Molecular modelling GLYCAM carbohydrate builder was used to construct ligands and auto-dock vina for antibody docking studies, both of which can be accessed at glycam.org.(38-40) PyMOL was used for visualisation and figure creation.

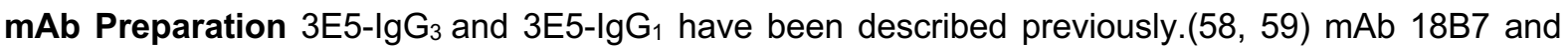
$2 \mathrm{H} 1$, were obtained as previously described. $(60,61)$ The murine mAbs were purified by protein $\mathrm{A}$ or $\mathrm{G}$ affinity chromatography (Pierce) from hybridoma cell culture supernatants and concentrated and buffer exchanged against $0.1 \mathrm{M}$ Tris- $\mathrm{HCl} \mathrm{pH}$ 7.4. mAb concentration was determined by $\mathrm{OD}_{280}$ measurement.

Capsule digestion experiments $C$. neoformans cultures were grown to stationary phase under capsule-inducing conditions in minimal media (2 days). Starting culture conditions were complete in Sabouraud medium. Cells were collected and heat-killed at $60{ }^{\circ} \mathrm{C}$ for $1 \mathrm{~h}$. Complete killing was confirmed by plating on solid Sabouraud medium. Heat-killed cells were washed 5 times with PBS to remove any soluble polysaccharide and cells were collected by ultracentrifugation $(4,000 \times \mathrm{g}, 5 \mathrm{~min}, 4$ $\left.{ }^{\circ} \mathrm{C}\right)$. Washed cells were suspended in a volume of PBS, which was divided equally between the four capsule digestion experiments: No mAb, control mAb (MOPC-31C, Sigma), 18B7, 2H1. All antibody incubations were carried out at $10 \mu \mathrm{g} / \mathrm{mL}$. Each sample was diluted with PBS, $\mathrm{pH} 7.0$, to a final volume of $2 \mathrm{~mL}$ and a concentration of $10^{6}$ heat-killed cells $/ \mathrm{mL}$. Samples were then incubated at $37^{\circ} \mathrm{C}$ with agitation. $C$. neoformans capsules were visualized at day 0 and at day 7 under light microscopy, by mixing $2 \mu \mathrm{L}$ of India ink with $6 \mu \mathrm{L}$ of cells. Images were taken with an Olympus AX 70 microscope. Capsule measurements were completed (Fiji, NIH, USA) and compared to day 0 and day 7 (No mAb). Statistical analysis (Ordinary one-way ANOVA) was performed in GraphPad Prism (Version 8, GraphPad Software, La Jolla, CA).

Immunofluorescence microscopy As previously reported (44) H99 C. neoformans cells were grown inoculated in Sabouraud dextrose medium for 2 days and then transferred to capsule inducing minimal media for 3 days. Cells were then heat killed at $60^{\circ} \mathrm{C}$ for 1 hour and incubated with the catalytic antibody $2 \mathrm{H} 1(10 \mu \mathrm{g} / \mathrm{mL})$ for 7 days. Samples were taken at timepoints indicated in figures. Cells were stained with the reducing-end hydroxylamine fluorescent probe $(2.5 \mu \mathrm{M}), 18 \mathrm{~B} 7(10 \mu \mathrm{g} / \mathrm{mL})$, or Complement $(20 \% \mathrm{w} / \mathrm{v})$. For indicated samples $2 \mathrm{H} 1$ was removed after the indicated incubation using Gentle $\mathrm{Ag} / \mathrm{Ab}$ 
Elution Buffer, pH 6.6 (Pierce Bioscience) Samples were incubated with indicated probe in blocking solution ( $1 \%$ bovine serum albumin (BSA) overnight at $30{ }^{\circ} \mathrm{C}$ in the dark. Cells were pelleted and washed to remove excess probe, 3 times in PBS plus 1\% BSA. Goat-anti-mouse anti-lgG1 secondary antibody - TRITC, Goat-anti-Complement C3 polyclonal - FITC or directly conjugated IgG1 18B7-Alexa Fluor 594 conjugate were added at $1 \mu \mathrm{g} / \mathrm{mL}$ for $1 \mathrm{~h}$, at $37^{\circ} \mathrm{C}$. After incubation cells were again washed 3 times with PBS plus $1 \%$ BSA. Uvitex2B was added to cells to stain the $C$. neoformans cell wall at a 1:10,000 dilution. Cells were then washed 3 times in PBS plus 1\% BSA. Cells were mounted on slides at $1 \times 10^{6} \mathrm{cell} / \mathrm{s} / \mathrm{mL}$ with Pro-Long Gold mounting solution (Molecular Probes). Channel exposures: FITC $(800 \mathrm{~ms})$ (ex:em 498/516 nm), TRITC (600 ms) (ex:em 540/580 nm) and DAPI (50 ms) (ex:em 350/450 $\mathrm{nm}$ ). Images were collected with an Olympus AX70 microscope, photographed with a QImaging Retiga 1300 digital camera using the QCapture Suite V2.46 software (QImaging, Burnaby BC, Canada), and processed with Image J from Fiji (NIH, USA).

Phagocytic Index Assay Phagocytosis was measured as previously reported.(62) Briefly, harvested and matured mouse BMDMs were plated at $5 \times 10^{5} \mathrm{cells} / \mathrm{mL} \sim 18 \mathrm{hrs}$ prior to experiment. HK H99 C. neoformans cells incubated 7 days with, or without $2 \mathrm{H} 1$ antibody were harvested. $2 \mathrm{H} 1 \mathrm{mAb}$ was removed by adding gentle $\mathrm{Ag} / \mathrm{Ab}$ elution buffer $(\mathrm{pH} 6.6)$ and incubating shaking at $37^{\circ} \mathrm{C}$ for 2 hours, then washing cells three times with TBS. 18B7 or Complement were added and incubated for 20 minutes prior to the addition of $C$. neoformans to the BMDMs. C. neoformans was added at a multiplicity of infection (MOI) of 3:1 to seeded macrophages and incubated for 2 hrs at $37{ }^{\circ} \mathrm{C}$ to allow for phagocytosis to occur. Cultures were gently washed 2x with BMDM media to remove nonphagocytosed CN. Cultures were visualized on a Carl Zeiss LSM 780 confocal microscope with a 403, 1.4 numerical aperture Plan Apochromat oil-immersion differential interference contrast objective and a spectral gallium arsenide phosphide detector in an enclosed chamber at 20x Brightfield. Acquisition parameters, shutters, and focus were controlled by ZEN Black software (Carl Zeiss).

\section{Acknowledgments}

We thank Dr Yannick Ortin and Dr Jimmy Muldoon for NMR and MS support. C.C was funded by Irish Research Council postgraduate award (GOIPG/2016/998). MPW was supported in part by Al007417. AC was supported in part by NIH grants Al052733-16, Al152078-01 and HL059842-19. S.O was supported by Science Foundation Ireland Award 13/IA/1959. 
References

1. A. Casadevall, Climate change brings the specter of new infectious diseases. J Clin Invest 130, 553 (2020).

2. A. Casadevall, E. Dadachova, L. A. Pirofski, Passive antibody therapy for infectious diseases. Nat. Rev. Microbiol. 2, 695-703 (2004).

3. J. Wentworth P., et al., Antibody catalysis of the oxidation of water. Science (80-. ). 293, 18061811 (2001).

4. A. Bowen, M. P. Wear, R. J. B. Cordero, S. Oscarson, A. Casadevall, A Monoclonal Antibody to Cryptococcus neoformans Glucuronoxylomannan Manifests Hydrolytic Activity for Both Peptides and Polysaccharides. J. Biol. Chem. 292, 417-434 (2017).

5. A. Janda, et al., Variable region identical IgA and IgE to Cryptococcus neoformans capsular polysaccharide manifest specificity differences. J. Biol. Chem. 290, 12090-12100 (2015).

6. A. Janda, E. Eryilmaz, A. Nakouzi, D. Cowburn, A. Casadevall, Variable region identical immunoglobulins differing in isotype express different paratopes. J. Biol. Chem. 287, 3540935417 (2012).

7. C. D. Gutsche, Catalysis in Chemistry and Enzymology. Science (80-. ). 168, 1080-1081 (1970).

8. B. Mets, et al., A catalytic antibody against cocaine prevents cocaine's reinforcing and toxic effects in rats. Proc. Natl. Acad. Sci. U. S. A. 95, 10176-10181 (1998).

9. P. G. Schultz, Catalytic Antibodies. Angew. Chemie Int. Ed. English 28, 1283-1295 (1989).

10. B. J. Park, et al., Estimation of the current global burden of cryptococcal meningitis among persons living with HIVIAIDS. AIDS 23, 525-530 (2009).

11. S. K. Chow, A. Casadevall, Evaluation of Cryptococcus neoformans galactoxylomannanprotein conjugate as vaccine candidate against murine cryptococcosis. Vaccine $\mathbf{2 9}, \mathbf{1 8 9 1 -}$ 1898 (2011).

12. S. Oscarson, M. Alpe, P. Svahnberg, A. Nakouzi, A. Casadevall, Synthesis and immunological studies of glycoconjugates of Cryptococcus neoformans capsular glucuronoxylomannan oligosaccharide structures. Vaccine 23, 3961-3972 (2005).

13. A. Nakouzi, T. Zhang, S. Oscarson, A. Casadevall, The common Cryptococcus neoformans glucuronoxylomannan M2 motif elicits non-protective antibodies. Vaccine 27, 3513-3518 (2009).

14. R. Cherniak, H. Valafar, L. C. Morris, F. Valafar, Cryptococcus neoformans chemotyping by quantitative analysis of $1 \mathrm{H}$ nuclear magnetic resonance spectra of glucuronoxylomannans with a computer-simulated artificial neural network. Clin. Diagn. Lab. Immunol. 5, 146-159 (1998).

15. S. Sheng, R. Cherniak, Structure of the 13C-enriched O-deacetylated glucuronoxylomannan of Cryptococcus neoformans serotype A determined by NMR spectroscopy. Carbohydr. Res. 301, 33-40 (1997).

16. R. Cherniak, J. B. Sundstrom, Polysaccharide antigens of the capsule of Cryptococcus neoformans. Infect. Immun. 62, 1507-12 (1994).

17. R. A. Larsen, et al., Phase I evaluation of the safety and pharmacokinetics of murine-derived anticryptococcal antibody 18B7 in subjects with treated cryptococcal meningitis. Antimicrob. Agents Chemother. 49, 952-958 (2005).

18. G. A. Nevinsky, V. N. Buneva, Catalytic antibodies in healthy humans and patients with autoimmune and viral diseases. J. Cell. Mol. Med. 7, 265-276 (2003).

19. A. Bowen, M. Wear, A. Casadevall, Antibody-mediated catalysis in infection and immunity. Infect. Immun. 85 (2017).

20. L. Guazzelli, et al., A synthetic glycan array containing Cryptococcus neoformans glucuronoxylomannan capsular polysaccharide fragments allows the mapping of protective epitopes. Chem. Sci. 11, 9209-9217 (2020).

21. A. Casadevall, et al., Antibodies elicited by a cryptococcus neoformans-tetanus toxoid conjugate vaccine have the same specificity as those elicited in infection. J. Infect. Dis. 165, 1086-1093 (1992).

22. S. J. N. Devi, et al., Cryptococcus neoformans serotype A glucuronoxylomannan-protein conjugate vaccines: Synthesis, characterization, and immunogenicity. Infect. Immun. 59, 
3700-3707 (1991).

23. L. Guazzelli, R. Ulc, S. Oscarson, Synthesis of benzyl protected $\beta-d-G l c A-(1 \rightarrow 2)-\alpha-d-M a n$ thioglycoside building blocks for construction of Cryptococcus neoformans capsular polysaccharide structures. Carbohydr. Res. 389, 57-65 (2014).

24. L. Guazzelli, R. Ulc, L. Rydner, S. Oscarson, A synthetic strategy to xylose-containing thioglycoside tri- and tetrasaccharide building blocks corresponding to Cryptococcus neoformans capsular polysaccharide structures. Org. Biomol. Chem. 13, 6598-6610 (2015).

25. P. J. Garegg, L. Olsson, S. Oscarson, Synthesis of oligosaccharides corresponding to structures found in capsular polysaccharides of crytococcus neoformans. Part 1. J. Carbohydr. Chem. 12, 955-967 (1993).

26. P. J. Garegg, L. Olsson, S. Oscarson, Synthesis of Oligosaccharides Corresponding to Structures Found in Capsular Polysaccharides of Cryptococcus Neoformans . Part 3. Two Regioselectively Acetylated Tetrasaccharides. J. Carbohydr. Chem. 16, 973-981 (1997).

27. M. Alpe, S. Oscarson, P. Svahnberg, Synthesis of Cryptococcus neoformans capsular polysaccharide structures. IV. Construction of thioglycoside donor blocks and their subsequent assembly. J. Carbohydr. Chem. 22, 565-577 (2003).

28. C. Crawford, S. Oscarson, Optimized Conditions for the Palladium-Catalyzed Hydrogenolysis of Benzyl and Naphthylmethyl Ethers: Preventing Saturation of Aromatic Protecting Groups. European J. Org. Chem., 3332-3337 (2020).

29. C. J. Crawford, S. Oscarson, Convergent total synthesis of Cryptococcus neoformans serotype B capsule repeating motif. Carbohydr. Res., 108150 (2020).

30. P. Fügedi, P. J. Garegg, A novel promoter for the efficient construction of 1,2-trans linkages in glycoside synthesis, using thioglycosides as glycosyl donors. Carbohydr. Res. 149, 9-12 (1986).

31. L. Guazzelli, R. Ulc, L. Rydner, S. Oscarson, A synthetic strategy to xylose-containing thioglycoside tri- and tetrasaccharide building blocks corresponding to Cryptococcus neoformans capsular polysaccharide structures. Org. Biomol. Chem. 13, 6598-6610 (2015).

32. C. Crawford, et al., Clues to a Pd/C catalyst's efficiency can be found on its surface: Identification of an efficient catalyst for the global hydrogenolysis of ether protecting groups. ChemRxiv (2020) https:/doi.org/10.26434/CHEMRXIV.12793634.V1 (August 12, 2020).

33. J. Mukherjee, A. Casadevall, M. D. Scharff, Molecular characterization of the humoral responses to cryptococcus neoformans infection and glucuronoxylomannan-tetanus toxoid conjugate immunization. J. Exp. Med. 177, 1105-1116 (1993).

34. R. Yuan, A. Casadevall, G. Spira, M. D. Scharff, Isotype switching from IgG3 to IgG1 converts a nonprotective murine antibody to Cryptococcus neoformans into a protective antibody. $J$. Immunol. 154, 1810-6 (1995).

35. S. A. K. Jongkees, S. G. Withers, Unusual enzymatic glycoside cleavage mechanisms. Acc. Chem. Res. 47, 226-235 (2014).

36. H. J. Rozeboom, et al., Crystal structure of $\beta-1,4-$ glucan lyase, a unique glycoside hydrolase family member with a novel catalytic mechanism. J. Biol. Chem. 288, 26764-26774 (2013).

37. A. C. M. Young, P. Valadon, A. Casadevall, M. D. Scharff, J. C. Sacchettini, The threedimensional structures of a polysaccharide binding antibody to cryptococcus neoformans and its complex with a peptide from a phage display library: Implications for the identification of peptide mimotopes. J. Mol. Biol. 274, 622-634 (1997).

38. S. Makeneni, D. F. Thieker, R. J. Woods, Applying Pose Clustering and MD Simulations to Eliminate False Positives in Molecular Docking. J. Chem. Inf. Model. 58, 605-614 (2018).

39. A. K. Nivedha, D. F. Thieker, S. Makeneni, H. Hu, R. J. Woods, Vina-Carb: Improving Glycosidic Angles during Carbohydrate Docking. J. Chem. Theory Comput. 12, 892-901 (2016).

40. A. K. Nivedha, S. Makeneni, B. L. Foley, M. B. Tessier, R. J. Woods, Importance of ligand conformational energies in carbohydrate docking: Sorting the wheat from the chaff. J. Comput. Chem. 35, 526-539 (2014).

41. V. Spiwok, $\mathrm{CH} / \pi$ interactions in carbohydrate recognition. Molecules 22 (2017).

42. D. L. Zechel, S. G. Withers, Glycosidase mechanisms: Anatomy of a finely tuned catalyst. Acc. Chem. Res. 33, 11-18 (2000). 
43. P. Bule, et al., Inverting family $\mathrm{GH} 156$ sialidases define an unusual catalytic motif for glycosidase action. Nat. Commun. 10, 1-11 (2019).

44. C. J. Crawford, et al., Exploring Cryptococcus neoformans capsule structure and assembly with a hydroxylamine-armed fluorescent probe. J. Biol. Chem. 295, 4327-4340 (2020).

45. O. Zaragoza, A. Casadevall, Monoclonal antibodies can affect complement deposition on the capsule of the pathogenic fungus Cryptococcus neoformans by both classical pathway activation and steric hindrance. Cell. Microbiol. 8, 1862-1876 (2006).

46. G. Y. Yang, et al., A FRET probe for cell-based imaging of ganglioside-processing enzyme activity and high-throughput screening. Angew. Chemie - Int. Ed. 54, 5389-5393 (2015).

47. S. Cecioni, D. J. Vocadlo, Carbohydrate Bis-acetal-Based Substrates as Tunable Fluorescence-Quenched Probes for Monitoring exo-Glycosidase Activity. J. Am. Chem. Soc 139, 53 (2017).

48. K. Sano, et al., Fluorescence Quenching-based Assay for Measuring Golgi endo- $\alpha-$ Mannosidase. Chem. - An Asian J. 14, 1965-1969 (2019).

49. H. Oka, T. Koyama, K. Hatano, K. Matsuoka, Synthetic studies of bi-fluorescence-labeled maltooligosaccharides as substrates for $\alpha$-amylase on the basis of fluorescence resonance energy transfer (FRET). Bioorganic Med. Chem. 20, 435-445 (2012).

50. J. C. Sistla, et al., Polymeric fluorescent heparin as one-step FRET substrate of human heparanase. Carbohydr. Polym. 205, 385-391 (2019).

51. A. Guerry, et al., Aniline-catalyzed reductive amination as a powerful method for the preparation of reducing end-"clickable" chitooligosaccharides. Bioconjug. Chem. 24, 544-549 (2013).

52. M. M. Kuttel, A. Casadevall, S. Oscarson, Cryptococcus neoformans Capsular GXM Conformation and Epitope Presentation: A Molecular Modelling Study. Molecules 25, 2651 (2020).

53. R. Vij, C. Danchik, C. Crawford, Q. Dragotakes, A. Casadevall, Variation in Cell Surface Hydrophobicity among Cryptococcus neoformans Strains Influences Interactions with Amoebas. mSphere 5 (2020).

54. M. Del Poeta, Role of phagocytosis in the virulence of Cryptococcus neoformans. Eukaryot. Cell 3, 1067-1075 (2004).

55. O. Zaragoza, et al., Chapter 4 The Capsule of the Fungal Pathogen Cryptococcus neoformans. Adv. Appl. Microbiol. 68, 133-216 (2009).

56. M. Kilcoyne, et al., Construction of a Natural Mucin Microarray and Interrogation for Biologically Relevant Glyco-Epitopes. Anal. Chem 84, 2020 (2012).

57. L. Guazzelli, R. Ulc, S. Oscarson, Synthesis of a Glucuronic Acid-Containing Thioglycoside Trisaccharide Building Block and Its Use in the Assembly of Cryptococcus Neoformans Capsular Polysaccharide Fragments. ChemistryOpen 4, 729-739 (2015).

58. M. Torres, N. Fernandez-Fuentes, A. Fiser, A. Casadevall, Exchanging Murine and Human Immunoglobulin Constant Chains Affects the Kinetics and Thermodynamics of Antigen Binding and Chimeric Antibody Autoreactivity. PLoS One 2, e1310 (2007).

59. T. K. Dam, M. Torres, C. F. Brewer, A. Casadevall, Isothermal titration calorimetry reveals differential binding thermodynamics of variable region-identical antibodies differing in constant region for a univalent ligand. J. Biol. Chem. 283, 31366-31370 (2008).

60. A. Casadevall, et al., Characterization of a murine monoclonal antibody to Cryptococcus neoformans polysaccharide that is a candidate for human therapeutic studies. Antimicrob. Agents Chemother. 42, 1437-1446 (1998).

61. R. A. Larsen, et al., Phase I evaluation of the safety and pharmacokinetics of murine-derived anticryptococcal antibody 18B7 in subjects with treated cryptococcal meningitis. Antimicrob. Agents Chemother. 49, 952-958 (2005).

62. S. C. Tucker, A. Casadevall, Replication of Cryptococcus neoformans in macrophages is accompanied by phagosomal permeabilization and accumulation of vesicles containing polysaccharide in the cytoplasm. Proc. Natl. Acad. Sci. U. S. A. 99, 3165-3170 (2002).

63. A. Varki, et al., Symbol nomenclature for graphical representations of glycans. Glycobiology 25, 1323-1324 (2015). 
A Reagents and Conditions: a) DMTST, $\mathrm{Et}_{2} \mathrm{O}, 4 \AA \mathrm{MS}, 0^{\circ} \mathrm{C} \rightarrow \mathrm{rt}, 80 \%$ : b) DDQ, $\mathrm{CH}_{2} \mathrm{Cl}_{2}: \mathrm{PBS}(100 \mathrm{mM}$, $\mathrm{pH} 7.5)(85: 15 \mathrm{v} / \mathrm{v}), 0^{\circ} \mathrm{C}, 76 \%$ : c) DMTST, Et $\mathrm{t}_{2} \mathrm{O}, 4 \AA \mathrm{MS}, 0^{\circ} \mathrm{C} \rightarrow \mathrm{rt}, 65 \%$ : d) DDQ, $\mathrm{CH}_{2} \mathrm{Cl}_{2}: \mathrm{PBS}(100 \mathrm{mM}$, $\mathrm{pH} 7.5)(85: 15 \mathrm{v} / \mathrm{v}), 0^{\circ} \mathrm{C}, 70 \%$. B Reagents and Conditions: a) $\mathrm{NaH} 60 \%$ dispersion in mineral oil, DMF, $4 \AA \mathrm{MS}$, PhthNCH $\mathrm{CH}_{2} \mathrm{CH}_{2} \mathrm{CH}_{2} \mathrm{Br}, 0^{\circ} \mathrm{C} \rightarrow \mathrm{rt}, 70 \%$ : b) DMTST, $\mathrm{Et}_{2} \mathrm{O}, 4 \AA \mathrm{MS}, 0^{\circ} \mathrm{C} \rightarrow \mathrm{rt}, 85 \%$ : c) ethylene diamine, $n-\mathrm{BuOH}, 90^{\circ} \mathrm{C}$ : d) $\mathrm{Boc}_{2} \mathrm{O}$, THF: $\mathrm{H}_{2} \mathrm{O}(70: 30 \mathrm{v} / \mathrm{v}), 57 \% 2$ steps: f) $\mathrm{Pd} / \mathrm{C}$ (pre-treated catalyst), $\mathrm{H}_{2}$, THF:tBuOH:PBS(100 mM, pH 5) (60:10:30 v/v/v), 66\%. 
Figure 1. Design and Synthesis of Glycan FRET Probes. A Glycan microarray data showing antibody binding is affected by acetylation of GXM in a concentration dependent manner $(200 \mu \mathrm{M}, 100$ $\mu \mathrm{M}, 50 \mu \mathrm{M})$. Bars represent the mean \pm SD. B Synthesis of two FRET probes. FRET-OAc 16 bears a 6 -O-acetylation pattern, while FRET 17 in contrast bears no acetylation pattern $\left({ }^{*}=\right.$ no $\left.6-O A c\right)$. Glycans are depicted according to symbol nomenclature for glycans (SNFG).(63) 
Table 1. Michaelis-Menten Kinetics of Catalytic Antibodies ${ }^{a}$

\begin{tabular}{|c|c|c|c|c|c|}
\hline Entry & Antibody & FRET Probe & $K_{m}[\mu \mathrm{M}]$ & $k_{\text {cat }}\left[\mathrm{s}^{-1}\right]$ & $\begin{array}{c}k_{\text {cat }} / K_{\mathrm{m}}[\mu \mathrm{M} \\
\left.1 / \mathrm{s}^{-1}\right]\end{array}$ \\
\hline 1 & $18 \mathrm{~B} 7$ & FRET & $35.8 \times 10^{-3}$ & $26.4 \times 10^{-3}$ & $7.3 \times 10^{-1}$ \\
\hline 2 & $2 \mathrm{H} 1$ & FRET & $54.7 \times 10^{-3}$ & $42.6 \times 10^{-3}$ & $7.7 \times 10^{-1}$ \\
\hline 3 & $3 \mathrm{E} 5-\lg \mathrm{G}_{1}$ & FRET & $55.7 \times 10^{-3}$ & $27.5 \times 10^{-3}$ & $7.4 \times 10^{-1}$ \\
\hline 4 & $3 E 5-\lg G_{3}$ & FRET & ND & ND & ND \\
\hline 5 & $18 \mathrm{~B} 7$ & FRET-OAc & $48.3 \times 10^{-3}$ & $25.7 \times 10^{-3}$ & $5.3 \times 10^{-1}$ \\
\hline 6 & $2 \mathrm{H} 1$ & FRET-OAC & $36.3 \times 10^{-3}$ & $33.5 \times 10^{-3}$ & $9.2 \times 10^{-1}$ \\
\hline 7 & $3 \mathrm{E} 5-\lg \mathrm{G}_{1}$ & FRET-OAc & $35.9 \times 10^{-3}$ & $26.7 \times 10^{-3}$ & $4.9 \times 10^{-1}$ \\
\hline 8 & $3 E 5-\lg G_{3}$ & FRET-OAC & $35.0 \times 10^{-3}$ & $29.0 \times 10^{-3}$ & $8.2 \times 10^{-1}$ \\
\hline
\end{tabular}

a The initial velocity $\left(\mathrm{V}_{0}\right)$ of each reaction was determined and plotted as a function of substrate concentration, the data was fit to the Michaelis-Menten equation for a single-step bimolecular reaction using nonlinear regression. $K_{\mathrm{m}}$ and $k_{c a t}$ were calculated using Prism 8. Each experiment was repeated in triplicate. 
Figure 2. A Glycan Based FRET Assay to Detect Catalytic Antibodies. 
Figure 3. Crystal Structure of 2H1 and GXM Peptide Mimotope P1 and Molecular Docking Studies with GXM. A Crystal structure of anti-GXM mAb 2H1. VH shown in light blue and VL light chain shown in pale green with docked GXM. B Calculated electrostatic surface potential of $2 \mathrm{H} 1$. Electrostatic surface potentials are colored red for negative charges, blue for positive charges, and white color represents neutral residues. Electrostatic surface potential was calculated using adaptive PoissonBoltzmann solve (APBS) in PyMOL. mAb 2H1 shows a positively charged cleft $(+10 \mathrm{kT}$ to $-10 \mathrm{kT})$. C GXM and P1 both adopt a helical conformation. Glycam Carbohydrate Builder was used to construct ligand. 
Figure 4. Absence of Classical Catalytic Residues in 2H1 Paratope. Hydrogen bonding interaction between $2 \mathrm{H} 1 \mathrm{mAb}$ and decasaccharide. 
Figure 5. Cells Incubated with Catalytic Antibodies have Reduced Capsule Diameter, Impaired Cellular Integrity, and the Appearance of Reducing Glycans in the Capsule from Polysaccharide Hydrolysis. A Heat-killed C. neoformans cells were incubated with $18 \mathrm{~B} 7,2 \mathrm{H} 1$, a control lgG ${ }_{1}$ antibody and no antibody for 7 days. Capsule measurements revealed a statistically significant (Ordinary oneway ANOVA) decrease in mean capsule diameter when incubated with $18 \mathrm{~B} 7$ or $2 \mathrm{H} 1$ but not in control experiments. Each group contained at least 100 capsule measurements ${ }^{* * * *}, p<0.0001$.) B Images of heat-killed fungal cells under each antibody condition at both day 0 and day 7 . India ink stain allows visualization of capsule diameter. Scale $10 \mu \mathrm{m}$. C Fluorescent microscopy of heat-killed C. neoformans cells incubated with 18B7, 2H1, anti-human IgG, or no antibody (no mAb) and imaged on day 3 and 7. An aminooxy probe was used to visualize the change in capsule architecture after exposure to catalytic antibodies over time (green) and capsule shown in red (goat anti mouse IgG FITC). Scale bar $5 \mu \mathrm{m}$. 
Figure 6. Physiological importance of 2H1-mediated capsule damage. A The effects of complement deposition on the capsule of heat killed H99 C. neoformans was examined after incubation with $2 \mathrm{H} 1 \mathrm{mAb}$ or no antibody for 7 days. Cells were stained with specific fluorophore conjugated secondary antibodies to visualize $\mathrm{mAb}$ and complement localization, Scale bar $6 \mu \mathrm{m}$. B Phagocytic opsonization was measured for untreated $\mathrm{H} 99 \mathrm{C}$. neoformans cells, cells treated with $2 \mathrm{H} 1 \mathrm{mAb}$ (with or without subsequent antibody removal) and guinea pig complement (with or without $2 \mathrm{H} 1$ treatment and removal). Statistically significant differences in phagocytic index where observed between untreated cells and all treatment conditions (Chi squared test for differences). The addition of complement to $\mathrm{H} 99 \mathrm{C}$. neoformans cells treated with $2 \mathrm{H} 1$ yields a highly significant increase in phagocytic index compared to cells only treated with $2 \mathrm{H} 1$, suggested that altered complement deposition as a result of catalytic $\mathrm{mAb}$ remodelling of the capsule diminishes the anti-phagocytic properties of the capsule. $\left({ }^{*}, p<0.5 ;{ }^{* *}, p<0.01 ;{ }^{* * *}, p<0.001\right)$. 
A

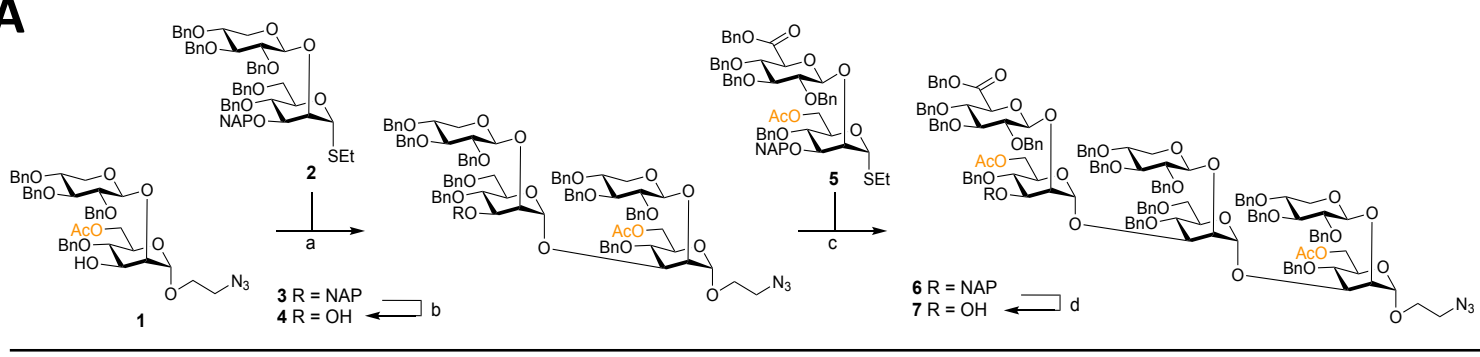

B
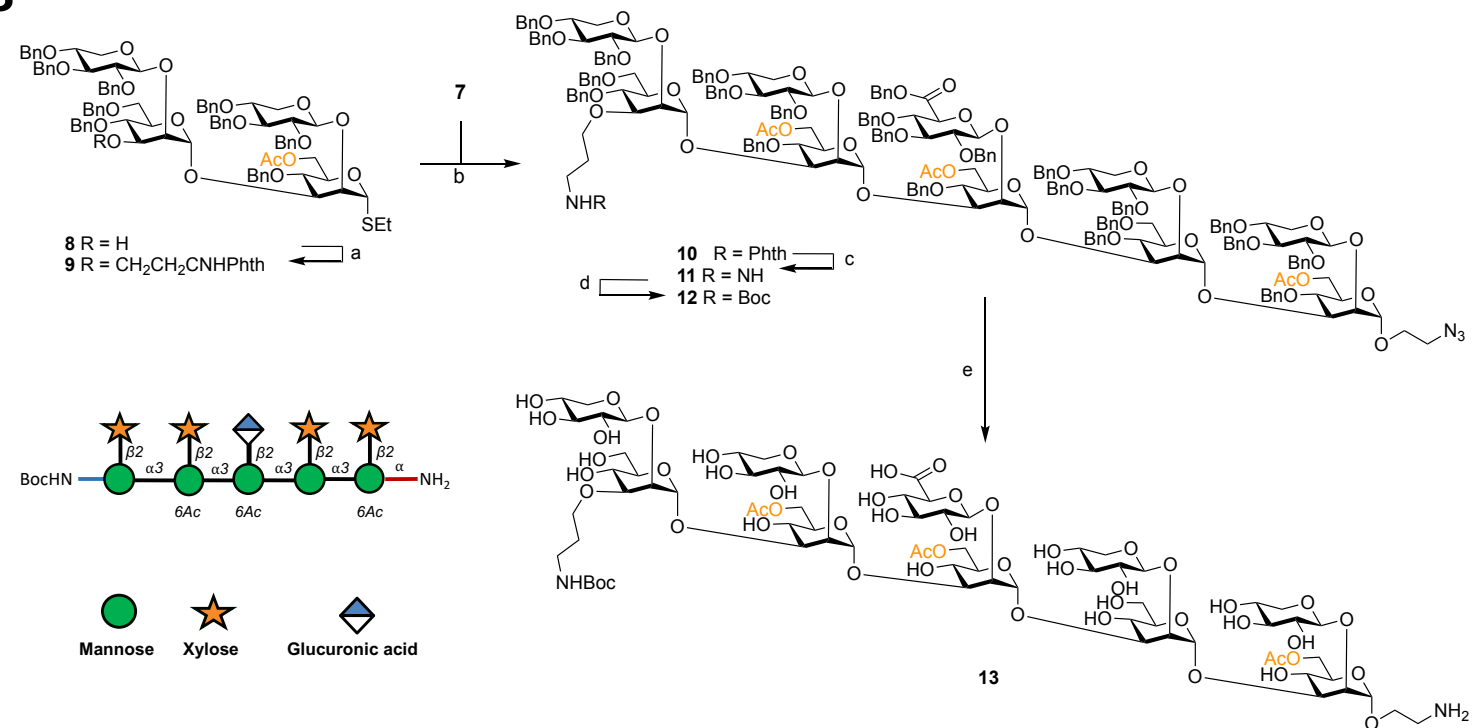

$\bigcup_{\text {Mannose }} \underbrace{}_{\text {Xylose }}$ 

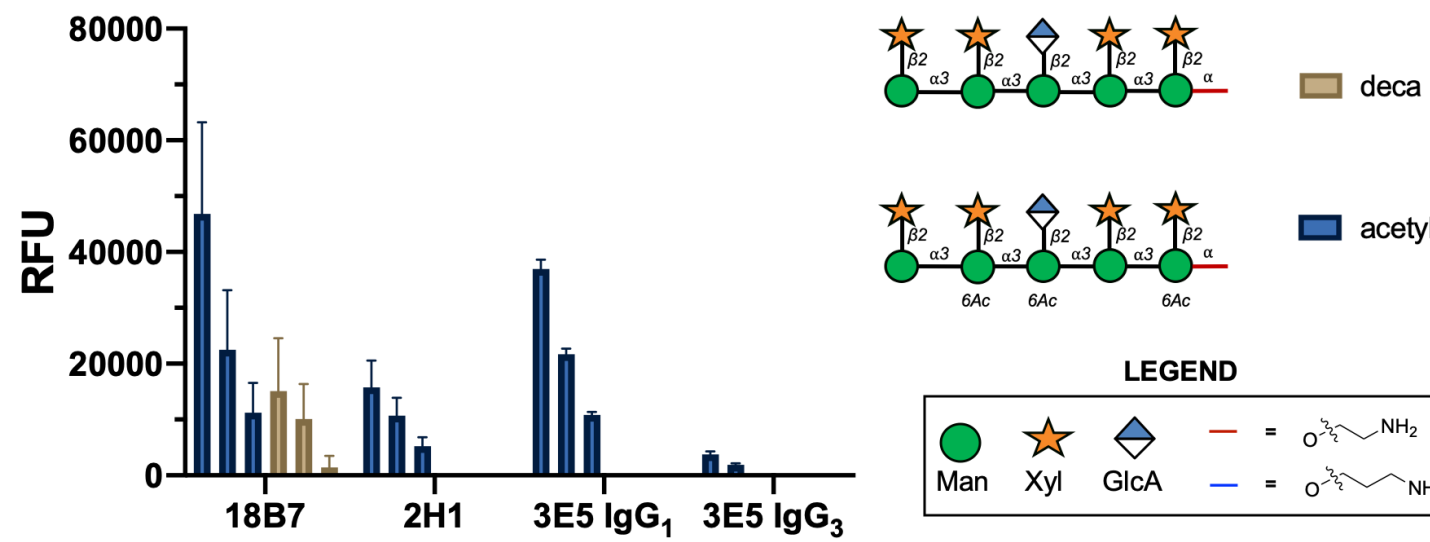

B

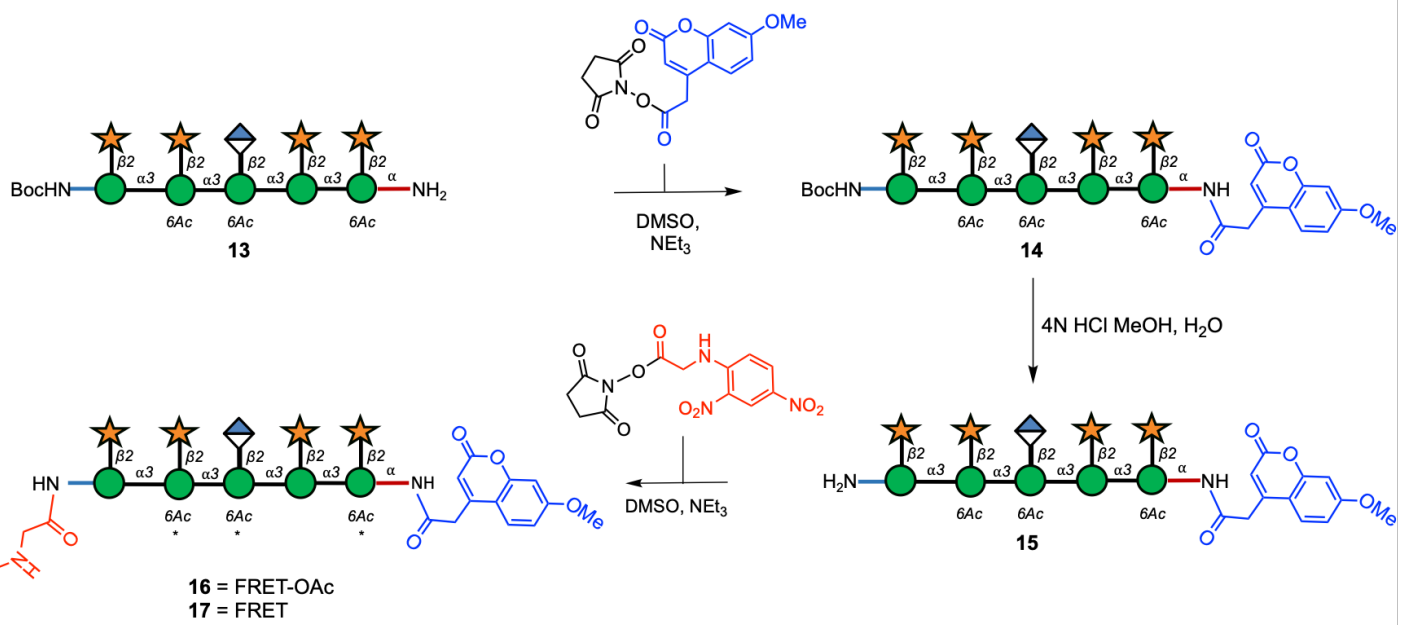


FRET-OAC

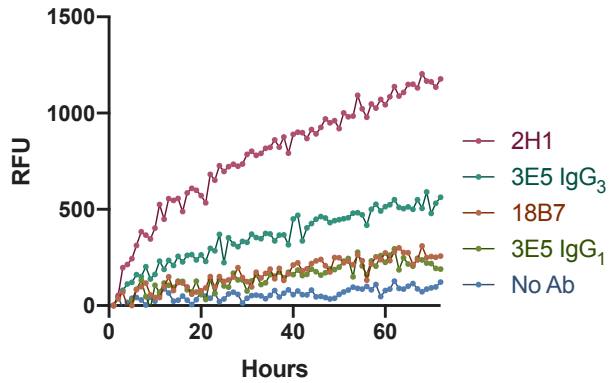

FRET

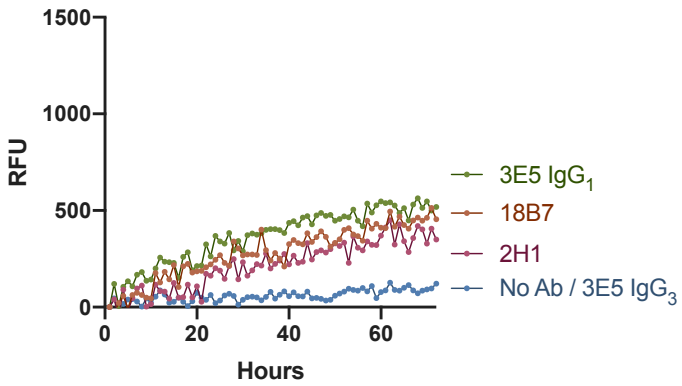


A
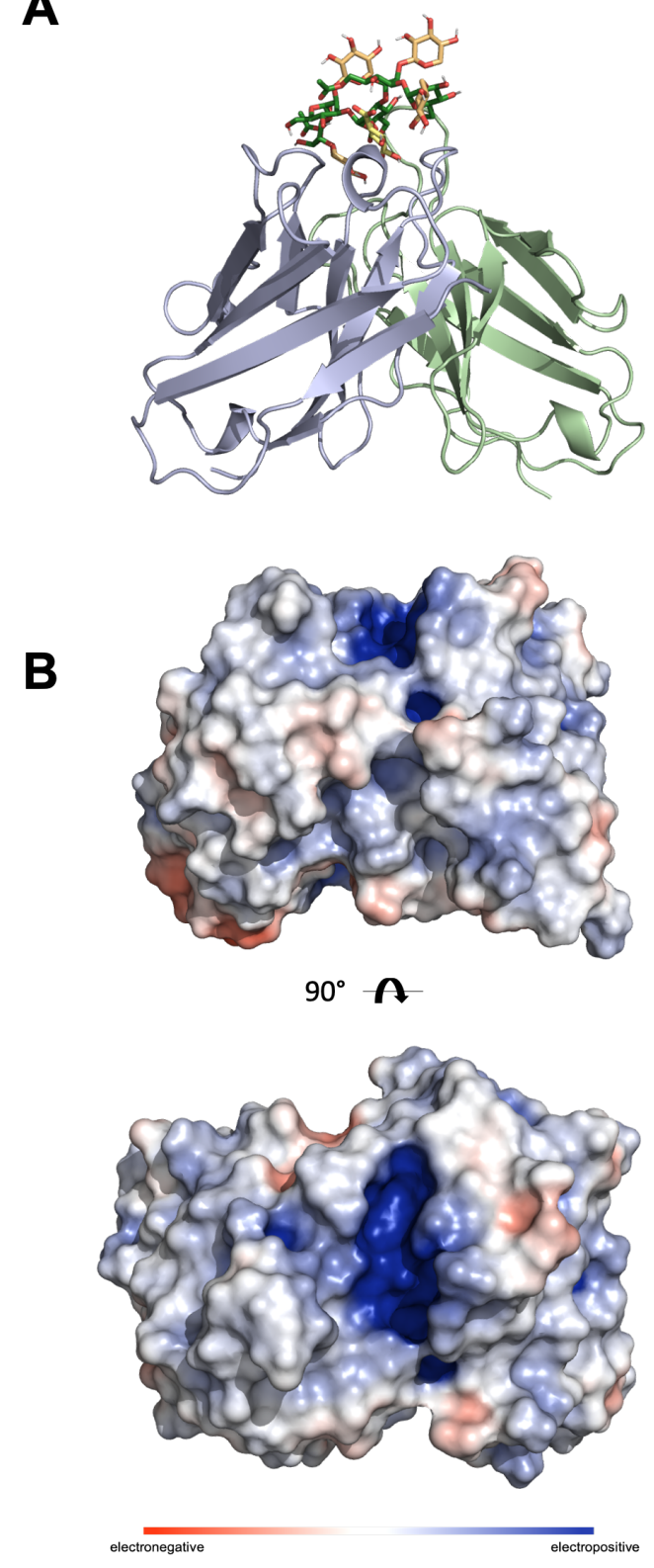

C

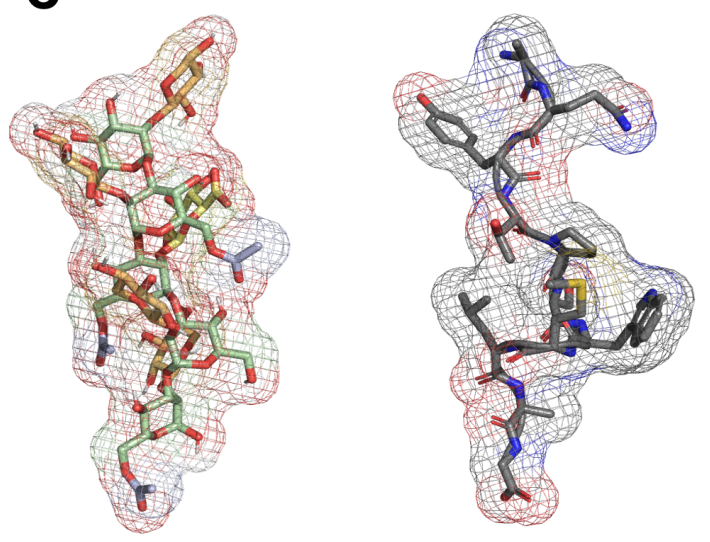

GXM

P1 


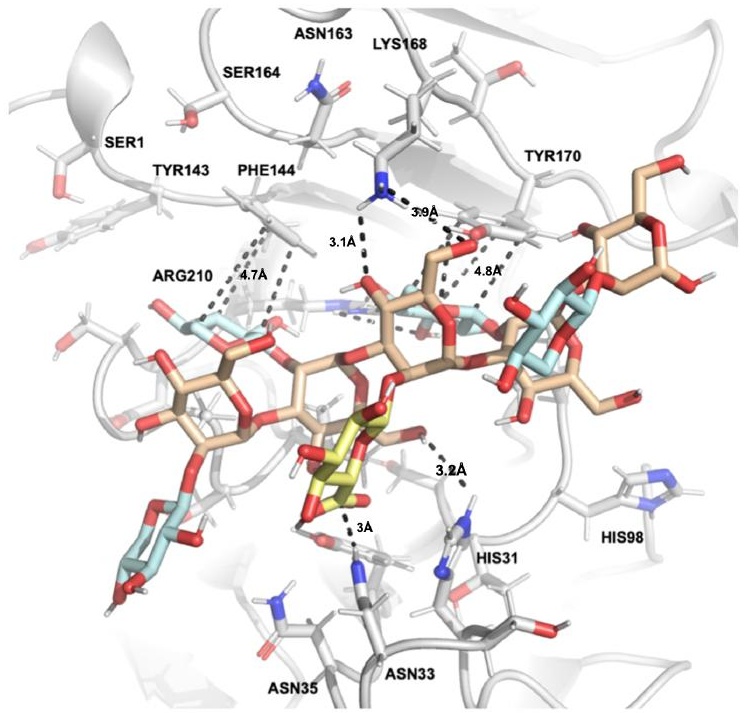


